\title{
VACUUM ASSISTED HYDROCOLLOID DRESSING - OUR EXPERIENCE
}

\author{
Vasudev Murthy Kumar ${ }^{1}$ Chethan Narayanappa ${ }^{2}$
}

${ }_{1}^{1}$ Associate Professor, Department of General Surgery, Akash Institute of Medical Sciences and Research Centre, Devanahalli. ${ }_{2}^{2}$ Assistant Professor, Department of General Surgery, Akash Institute of Medical Sciences and Research Centre, Devanahalli.

\begin{abstract}
BACKGROUND

Chronic ulcers are responsible for significant morbidity and mortality all over the world. Management of these ulcers is constantly updated with newer advancements and newer dressing materials. Vacuum-assisted hydrocolloid dressing (VAHCD) is one such dressing, which combines the advantages of hydrocolloid support with provision of sub-atmospheric pressure by vacuum. Our study is an attempt to evaluate the efficacy of VAHCD in large chronic ulcers.

The objective of this study is to evaluate the efficacy of VAHCD on large chronic ulcers.
\end{abstract}

\section{MATERIALS AND METHODS}

This study was conducted as descriptive study. Patients with ulcers more than $10 * 10 \mathrm{~cm}$ size, who attended in the dept. were included in the study. Patient's consent was taken. All these patients were done VAHCD and results were recorded.

\section{RESULTS}

28 patients were included in the study, of which 13 were of 2 to 6 months duration. 20 ulcers were of size from 10 to $20 \mathrm{~cm}$ in largest dimension. After dressing with VAHCD, majority of ulcers showed more than $1 \mathrm{~cm}$ decrease in size per dressing and depth of ulcers were filled up within 1 - 2 dressings.

\section{CONCLUSION}

Vacuum-Assisted Hydrocolloid Dressing is an efficient and overall cost-effective method in management of chronic ulcers.

\section{KEYWORDS}

Vacuum-Assisted Hydrocolloid Dressing (VAHCD), Chronic Ulcer, Subatmospheric Pressure.

HOW TO CITE THIS ARTICLE: Kumar VM, Narayanappa C. Vacuum Assisted Hydrocolloid Dressing - Our Experience. j. Evolution Med. Dent. Sci. 2018;7(10):1271-1274, DOI: 10.14260/jemds/2018/290

\begin{abstract}
BACKGROUND
The association of chronic foot ulcers with a high incidence of amputation, morbidity and mortality is well documented in the International Literature including guidelines from the American Diabetes Association, the International Consensus Panel of Diabetic Ulcers, and the German Literature on Diabetic Foot Syndrome.1,2,3 A brief review of the pathophysiology of diabetic ulcers and an understanding of the chronic wounds will facilitate decisions related to the use of new technologies. The following overview of new technology related to diabetic foot ulcer care will summarise relevant information related to chronic wounds and assist in defining a chronic wound and its management using vacuumassisted hydrocolloid dressing. VAHCD is a non-invasive procedure that utilises negative pressure to remove fluid from the open wounds through sealed dressings.
\end{abstract}

\section{Chronic Wound Healing}

The cellular mechanism of wound repair in the acute wound has been extensively studied and documented in the medical literature.4,5,6 The inflammatory, proliferative (Granulation phase) and remodelling phases can be categorised according

'Financial or Other Competing Interest': None.

Submission 09-02-2018, Peer Review 21-02-2018,

Acceptance 23-02-2018, Published 05-03-2018.

Corresponding Author:

Dr. Vasudev Murthy Kumar,

\#525, Tank Road, Doddballapur-561203,

Bangalore Rural District.

E-mail: murthy_dbp@yahoo.com

DOI: $10.14260 /$ jemds $/ 2018 / 290$ to the activity of their cellular components including cytokines, chemical mediators and cellular components. ${ }^{7}$ Intrinsic medical conditions or extrinsic environmental factors rarely affect the repair process in the healthy individual. The chronic wound, in contrast to the above, has phases of repair that do not follow the expected sequence of healing. Wound treatment experts in the United States have made attempts to define chronic wounds. ${ }^{8}$ Intrinsic, extrinsic and wound environment factors must be simultaneously treated for optimal outcomes. Intrinsic factors include the patient's medical status, prescribed medications and concomitant disease. Extrinsic factors concern repetitive trauma, off-loading and pressure reduction.

\section{Definition of Chronic Wounds}

$15 \%-20 \%$ of patients with chronic wounds does not respond to conventional therapy and may require the use of advanced technologies to stimulate and expedite tissue repair. The surgeon needs to differentiate between a responding chronic wound, which will close with conventional treatment and a truly non-responding wound which will require a different approach such as vacuum-assisted hydrocolloid dressing.

Pecoraro et al $^{9}$ determined that not all diabetic ulcers are responders. Those ulcers not showing a reduction in size in a one-month treatment period with good pressure reduction and ulcer therapy can be classified as non-responders. Furthermore, Silhi et al ${ }^{10}$ determined that approximately $15 \%$ of all diabetics under good control would still not demonstrate normal healing rates. The delay in wound repair may be attributable to endogenous wound factors including senescent cells, absence of growth factors and other cellular abnormalities. Debridement of senescent cells, non-viable 
tissue, fibrotic tissue, wound debris and other unwanted wound components may significantly expedite wound closure, while increasing the availability of viable cells able to produce and respond to growth factors and other cytokines. Debridement and its correlation to the significant increase in wound closure, particularly when followed by the application of negative pressure to wound bed. The presence of a prolonged inflammatory response may further delay closure by promoting ongoing activity of matrix-metalloproteinases (MMP). High levels of MMP activity may contribute to protein and growth factor degradation. Repetitive trauma and high levels of bacterial colonisation may result in increased inflammation activity with an associated influx of macrophages and neutrophils, the negative pressure helps in decreased bacterial burden from the wound. Appropriate levels of MMP activity during the phases of wound repair are known to promote wound repair, while prolonged levels may delay closure through matrix, growth factor and growth factor receptor degradation. ${ }^{11}$

\section{Advanced Technology for Chronic Ulcers}

The use of advanced technology like vacuum-assisted hydrocolloid dressing may assist with wound closure in the diabetic and non-diabetic patient. Based on medical literature, the clinician should be able to determine within the first few weeks of treatment whether a wound will respond to conventional therapies (responders) or remain chronic (non-responder). Available literature suggests that a visible decrease in wound size during the first few weeks of administering appropriate wound care is an indicator of chronicity. Wounds that decrease in size by greater than $0.109 \mathrm{~cm}$ per week have been found to correlate with responsive wounds, while rates less than $0.032 \mathrm{~cm}$ per week are classified as non-responders. ${ }^{12} \mathrm{~A}$ decrease in surface area of less than $10 \%$ per month may also correlate with nonresponding chronic wounds. Once a surgeon has established the status of a wound as being chronic, advanced modalities may be selected to improve treatment and cost outcomes.

\section{Vacuum-Assisted Hydrocolloid Dressing- Relevance to Chronic Foot Ulcers}

Application of sub-atmospheric pressure to wound bed was proposed more recently in 1993 by Fleischmann and colleagues. Chen and colleagues showed that vascular endothelial cell growth (VEGF) factor pathway was stimulated. Hydrocolloid is a gel forming agent that contains Sodium carboxymethylcellulose, Gelatin. This formulation is combined with elastomers, adhesives and spread over a polyurethane foam. This hydrocolloid sheet forms an absorbent, self-adhesive, waterproof wafer and a wet tack. They absorb exudates and form a less viscous mobile gel, which is sucked out of the dressing. This dressing removes exudates from wounds by negative pressure of about 15 - 20 $\mathrm{mmHg}$, decreases bacterial burden, provides a moist environment, reduces the peripheral oedema around the ulcer, promotes angiogenesis, helps in early closure of the wound. Indications for VAHCD include Acute, Chronic and traumatic Ulcers, Ulcers free of necrotic tissue and Pressure ulcers.

\section{Objective}

To evaluate the efficacy of VAHCD on large chronic ulcers.

\section{MATERIALS AND METHODS}

The study was conducted as descriptive study over 02 years from June 2014 to May 2016. Patients presenting to hospital with chronic lower limb ulcers of size more than $10 * 10 \mathrm{~cm}$, both diabetic and non-diabetic wounds were included in the study. Chronic ulcers are defined as ulcers of more than 4 weeks duration. Patients with smaller ulcers, acute ulcers, ulcers with osteomyelitis and malignant ulcers were excluded from the study. Preliminary data was obtained.

\section{VAHCD Procedure}

The wound is debrided first and made free of necrotic tissue, under local anaesthesia closed suction drain was inserted, hydrocolloid sheet was fashioned to cover the entire wound with $1 \mathrm{~cm}$ covering over the margin of the wound. This is further covered with transparent adhesive dressing (opsite). A regular dressing is done over this. Negative suction is applied continuously.

Drains are discarded daily. Wound inspection was done on 4th - 5th day and dressing was changed entirely. Supportive measures were provided in the form of control of diabetes, immobilisation of the part, sensitivity based antibiotics, nutritional supplementation and drain care. Changes were documented based on size of the wound, granulation tissue, depth of the wound and surrounding skin texture. The results were tabulated. Once the size of wound was reduced or 6 - 8 VAHCD dressings were attempted, ulcers were managed with regular dressings, secondary suturing and split skin grafting.

These procedures were both as an inpatient and outpatient basis. All these patients were followed up for 6 months after complete closure of ulcers.

\section{RESULTS}

A total of 28 cases were included in the study. The general characteristics of these patients are as shown in table.

\begin{tabular}{|c|c|c|c|}
\hline Sl. No. & General Characteristics & Size & Percent \\
\hline & Age: & & \\
01 & $<20$ & 0 & 0 \\
& $20-40$ & 15 & 53.5 \\
& $>40$ & 13 & 46.5 \\
\hline & Total & $\mathbf{2 8}$ & $\mathbf{1 0 0}$ \\
\hline \multirow{3}{*}{02} & Sex: & & \\
& Male & 25 & 89 \\
& Female & 03 & 11 \\
\hline & Total & $\mathbf{2 8}$ & $\mathbf{1 0 0}$ \\
03 & Duration of ulcer: & & \\
& 4 wks to 2 months & 12 & 43 \\
& 2 to 6 months & 13 & 46 \\
& $>6$ months & 03 & 11 \\
\hline & Total & $\mathbf{2 8}$ & $\mathbf{1 0 0}$ \\
04 & Diabetes: & 18 & 64 \\
& Present & 10 & 36 \\
\hline & Absent & $\mathbf{2 8}$ & $\mathbf{1 0 0}$ \\
\hline
\end{tabular}

The size of the ulcers (larger dimensionvertical/horizontal) prior to VAHCD were as follows-

$$
10 \text { to } 20 \mathrm{~cm} \quad-20(71.5 \%)
$$$$
>20 \mathrm{~cm} \quad-08(28.5 \%)
$$ 
All the patients were done VAHCD after debriding the necrotic tissue. Dressing was done as described earlier and was changed once in 03 to 05 days depending on soakage of dressing. The response noted were as follows-

\section{Change in Size of ulcers-}

\section{After 1 st Dressing}

$$
\begin{aligned}
& >2 \mathrm{~cm} \quad-10(36 \%) \\
& >\quad 01-02 \mathrm{~cm} \quad-\quad 18(64 \%) \\
& ><01 \mathrm{~cm}-00
\end{aligned}
$$

\section{After 2nd Dressing}

$$
\begin{aligned}
& >\quad>2 \mathrm{~cm} \\
& >\quad 01-02
\end{aligned}
$$

Number of Dressings for ulcer to reach $<\mathbf{5} \mathbf{~ c m}$ size

$$
\begin{aligned}
& >\quad 07-08 \quad-06(21.5 \%) \\
& >\quad 04-06 \quad-\quad 16(57 \%) \\
& >02-03 \quad-02(21.5 \%)
\end{aligned}
$$

04 cases which were $>05 * 05 \mathrm{~cm}$ even after 08 dressings were posted for split skin grafting. Depth of ulcers covered till surface within 01 - 02 dressings. Average duration of hospital stay for these patients was 8.5 days (range from 04 to 25 days).

The result of VAHCD on ulcer is shown in Photo 1 and 2 .

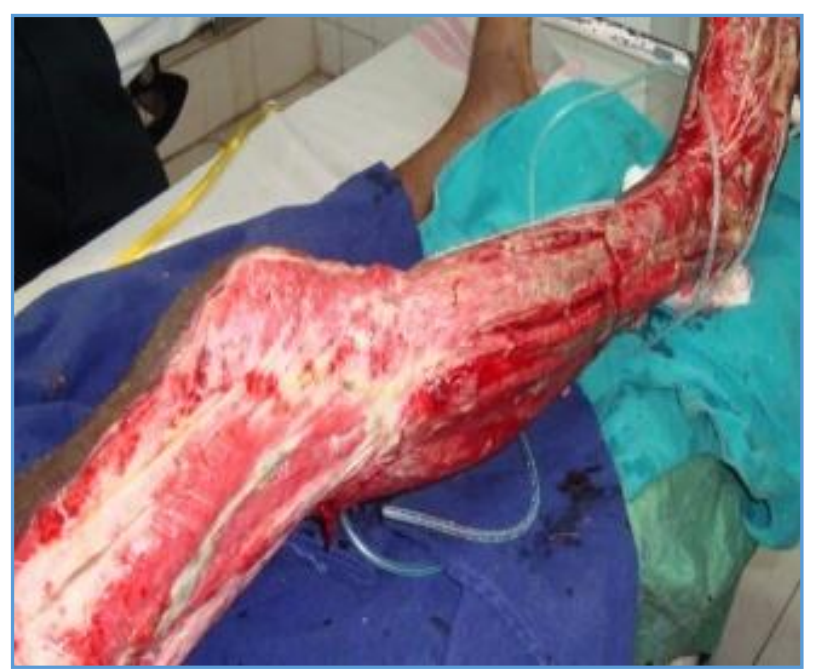

$$
\begin{aligned}
& \text { Photo 1. Ulcer following Debridement of } \\
& \text { Necrotising Fasciitis (6 Wks Old) }
\end{aligned}
$$

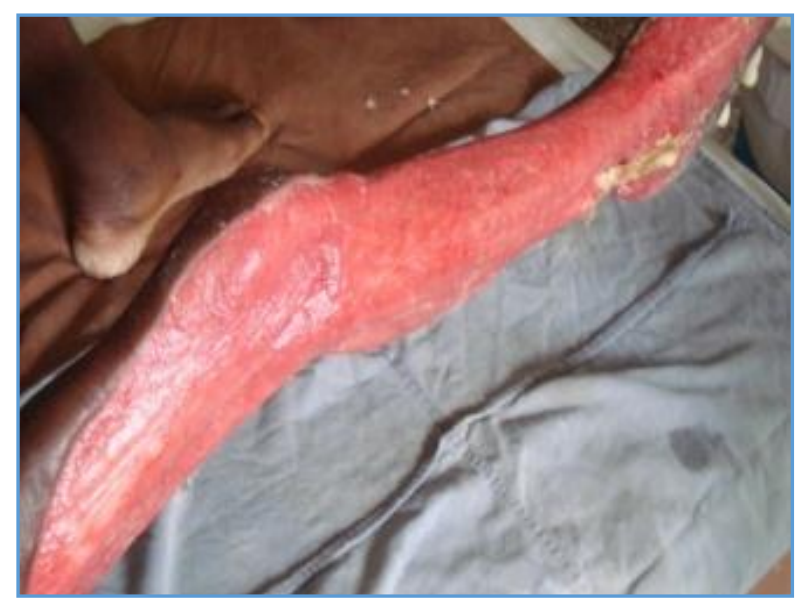

Photo 2. Changes Seen in Ulcer after Two VAHCD

\section{DISCUSSION}

Fleischmann and colleagues described the use of vacuumassisted closure in treatment of 25 patients with compartment syndromes of the lower limb. The average duration of the vacuum therapy treatment for the patients with compartment syndrome was 12.7 (4 - 31) days with 2.1 (1 - 8) dressing changes per patient. These wounds were subsequently either closed by secondary suturing $(n=20)$ or by skin grafts following partial closure by suturing $(n=5) .13$

Same author also published the use of same in 313 patients with acute and chronic infections of various types. The average duration of vacuum therapy in the treatment of the 313 patients with infected wounds was 16.7 days with an average of 3.1 dressing changes. Of the 203 wounds with acute infections, the majority were subsequently closed by secondary suturing $(65.5 \%)$ and the remainder by spontaneous epithelialisation (17.2\%), skin grafting (12.3\%) or flap transfer (2\%). Six patients $(3 \%)$ died. Infection recurred in $3.9 \%$ and was managed using another treatment.14 Though this study shows lesser number of dressings per patient and use of secondary suturing, our study focused on large ulcers and hence they required more dressings.

Mullner et al described the results of a prospective trial involving 45 patients with soft tissue injuries with use of vacuum-assisted closure techniques. They reported that in $38 / 45$ patients $(84 \%)$ the use of the vacuum sealing technique following irrigation and debridement decreased the dimensions of the initial wound, thus facilitating healing time and the eradication of any pre-existing infection. ${ }^{15}$

Papers on use of vacuum-assisted closure of wound in pressure sores, skin grafting, wound dehiscence and other wounds have been published.16,17,18

\section{The Advantages of VAHCD that we have noticed are-}

- Can be done on an outpatient basis as the regular dressings.

- Regular wound dressing is not required.

- Rate of granulation is faster and decreases the duration of hospital stay.

- Wound contamination is prevented.

- Compliance of the patient is good.

\section{CONCLUSION}

Vacuum-Assisted Hydrocolloid Dressing is an efficient and overall cost-effective method in management of chronic ulcers.

\section{REFERENCES}

[1] American Diabetes Association. Consensus Development Conference on Diabetic Foot Wound Care: 7-8 April 1999, Boston, Massachusetts. American Diabetes Association. Diabetes Care 1999;22(8):135460 .

[2] International Working Group on the Diabetic Foot. International Consensus on the Diabetic Foot. Netherlands, 1999. diabetic-foot@mail.com

[3] Reike H. Diabetisches fuss-syndrome. Berlin: Walter de Gruyter 1999:1-13.

[4] Kerstein MD. The scientific basis of healing. Adv Wound Care 1997;10(3):30-6. 


\section{Jemds.com}

[5] Witte MB, Barbul A. General principles of wound healing. Surg Clin North Am 1997;77(3):509-28.

[6] Kane DP, Krasner D. Wound healing and wound management. In: Krasner D, Kane D, eds. Chronic wound care: a clinical source book for healthcare professionals. $2^{\text {nd }}$ edn. Wayne, PA: Health Management Publications, Inc 1997.

[7] Hunt TK, Hopf H, Hussain Z. Physiology of wound healing. Adv Skin Wound Care 2000;13(2 Suppl):6-11.

[8] Lazarus GS, Cooper DM, Knighton DR, et al. Definitions and guidelines for assessment of wounds and evaluation of healing. Arch Dermatol 1994;130(4):489-93.

[9] Pecoraro R, Ahroni JH, Boyko EJ, et al. Chronology and determination of tissue repair in diabetic lowerextremity ulcers. Diabetes 1991;40(10):1305-13.

[10] Silhi N. Diabetes and wound healing. J Wound Care 1998;7(1):47-51.

[11] Mast BA, Schultz GS. Interactions of cytokines, growth factors, and proteases in acute and chronic wounds. Wound Repair Regen 1996;4(4):411-20.

\section{Original Research Article}

[12] Bello Y, Phillips TJ. Predictors of wound healing. J Clin Dermatol 1999;2:39-43.

[13] Fleischmann W, Lang E, Kinzl L. Vacuum assisted wound closure after dermatofasciotomy of the lower extremity. Unfallchirurg 1996;99(4):283-7.

[14] Fleischmann W, Lang E, Russ M. Treatment of infection by vacuum sealing. Unfallchirurg 1997;100(4):301-4.

[15] Mullner T, Mrkonjic L, Kwasny O, et al. The use of negative pressure to promote the healing of tissue defects: a clinical trial using the vacuum sealing technique. Br J Plast Surg 1997;50(3):194-9.

[16] Baynham SA, Kohlman P, Katner HP. Treating stage IV pressure ulcers with negative pressure therapy: a case report. Ostomy Wound Manage 1999;45(4):28-32, 345.

[17] Molnar JA, DeFranzo AJ, Marks MW. Single-stage approach to skin grafting the exposed skull. Plast Reconstr Surg 2000;105(1):174-7.

[18] Smith LA, Barker DE, Chase CW, et al. Vacuum pack technique of temporary abdominal closure: a fouryear experience. Am Surg 1997;63(12):1102-7. 